\title{
Clustering Penerima Beasiswa Yayasan Untuk Mahasiswa Menggunakan Metode K-Means
}

\author{
Bernadus Gunawan Sudarsono*, Sri Poedji Lestari \\ Program Studi Sistem Informasi, Universitas Bung Karno, Jakarta, Indonesia \\ Email Penulis Korespondensi: gunawanbernadus@ubk.ac.id
}

\begin{abstract}
Abstrak-Pengelompokan penerima beasiswa Bantuan beasiswa akan dibuat berdasarkan nilai yang diakumulasikan menggunakan clustering dimana penerima beasiswa ini akan diberikan beasiswa dengan jumlah dan besaran yang berbeda, dikarenakan beasiswa dari yayasan terbatas dan memiliki tingkatan terhadap pembagiannya. Pembagian kelompok terhadap mahasiswa penerima beasiswa dari yayasan menggunakan metode clustering dari data mining dimana fungsi dari clustering yaitu cluster atau tugas mengkelomppokan suatu hal menggunakan pendekatan algoritma clustering yaitu algoritma K-means. Hasil dari clustering ini menunjukan mahasiswa berdasarkan kelompoknya terbagi atas empat golongan berdasarkan jumlah dari kriteria, hasil pengelompokan memperlihatkan jumlah dan keputusan yayasan terhadap pemberian beasiswa yayasan terhadap mahasiswanya.
\end{abstract}

Kata Kunci: Clustering; K-Means; Penerima Beasiswa.

Abstract-Grouping of scholarship recipients Scholarship assistance will be made based on the accumulated value using clustering where the scholarship recipients will be given scholarships with different amounts and sizes, because scholarships from foundations are limited and have levels of distribution. The division of groups to students who receive scholarships from foundations uses the clustering method of data mining where the function of clustering is a cluster or the task of grouping something is using the clustering algorithm approach, namely the K-means algorithm. The results of this clustering show that students based on their groups are divided into four groups based on the number of criteria, the results of the grouping show the number and decision of the foundation on granting foundation scholarships to students.

Keywords: Clustering; K-Means; Scholarship Grantee

\section{PENDAHULUAN}

Banyaknya anak-anak bangsa Indonesia yang memiliki kemampun belajar yang baik dan keinginan belajar yang tinggi tetapi terhalang karena sulinya keuangan dan himpitan ekonomi yang dihadapi oleh mahasiswa dan keluarganya, pemerintah mendirikan program danan bantuan berupa beasiswa .Beasiswa dapat membantu banyak kalangan dalam menyelesaikan kesulitan ekonomi bagi pelajar-pelajar yang ingin meneruskan keinginan belajar untuk lanjut kejenjang pendidikan lebih tinggi[1], beasiswa memiliki banyak jenis yang disediakan pihak dalam negeri maupun luar negeri, pihak swasta maupun pihak pemerintahan demi mencapai satu tujuan bersama yaitu mencerdasrkan kehidupan bangsa melalui cikal bakal generasi terdidik terutama pada bidang pendidikan di jenjang perguruan tinggi[2].

Jenis beasiswa seperti beasiswa penghargan seperti mengikuti suatu kontestan atau ajang yang menampilkan bakat dan emenangnya diberikan hadiah dan dana beasiswa, beasiswa bantuan bisa jadi beasiswa ini diberikan oleh donator atau warga yang mampu ingin membantu seseorang dalam dunia pendidikannya, penelitian, akademik seperti beasiswa atass prestasi maupun bantuan dari pihak yayasan, non akademik, dinas, dan berdasarkan sumber dana beasiswa dibagi atas beberapa seperti beasiswa dari pemerintahan yaitu Bidikmisi, LPI, BAPPENAS, LPDP. Beasiswa dari negara maju seperti Chevening (Inggris), Fulbright (Amerika serikat), Beasiswa Nuffic Neso (NEC) (Belanda), dan lain-lain. Beasiswa komunitas dan yayasan[3][4].

Beasiswa yayasan adalah bantuan yang di berikan oleh pihak perguruan tinggi untuk diperuntukan kepada mahasiswa yang berasal dari kalangan yang kurang mampu, berprestasi maupun aktif agar mahasiswa tersebut tetap bisa melanjutkan ke perguruan tinggi. Beasiswa ini di salurkan melalui perguruan tinggi dan berada di bawah donator pihak yayasan maupun perguruan tinggi itu sendiri. Untuk seleksi pendaftaran beasiswa. Untuk penyaluran beasiswa yayasan ini kepada mahasiswa baru ini juga harus memperhatikan syarat-syarat tertentu sebelum beasiswa itu di berikan kepada mahasiswa yang bersangkutan[5].

Untuk syarat yang harus di penuhi seperti penghasilan orang tua, displin mahasiswa, prestasi akademik di dalam mauun luar lingkungan kampus dan juga prerstasi mahasiswa dan IPK yang mahasiswa miliki. Di dalam masalah untuk menentukan penerima beasiswa yayasan yang akan dikelomokan untuk mendapatkan data dan hasil yang lebih tepat dari nilai-nilai yang dimiiki peserta penerima beasiswa akan menggunakan Algoritma Kmeans yang di mana akan mengkelompokan dan membagi data yang ada. Algortima ini akan membagi data kedalam bentuk cluster sehingga jika ada data yang sama dan mengantisipasi tidak terjadi kesenjangan dalam pembagian beasiswa dengan data yang memiliki nilai yang berbeda satu sama lain[6].

Tujuan dari penelitian ini menggunakan algoritma K-means yang di mana di gunakan untuk membantu perhitungan nilai kemurniannya dari hasil clustering yang dilakukan. Dan juga tujuan dilakukan nya penelitian ini untuk membantu klasterisasi pengusulan mahasiswa yang layak dan tidak layak untuk menerima beasiswa dengan 4 syarat yaitu penghasilan orang tua, disiplin, IPK (indek prestasi kumulatif), dan prestasi mahasiswa di 
bidang akademi. Dan yang mana bertujuan untuk mempermudah melihat hasil dari nilai kemurniannya dari hasil clustering tersebut[7].

Penggunaan metode ini dilakukan karena sudah banyak penelitian terhadap pengelompokan suatu hal menggunakan clustering dan pendekatan algoritma K-means seperti "Penerapan Clustering Pada Penduduk Yang Mempunyai Keluhan Kesehatan Dengan Datamining K-Means"[8], Selanjutnya Terdapat Pada Penelitian "Implementasi K-Means Clustering Ujian Nasional Sekolah Menengah Pertama Di Indonesia Tahun 2018", "Sistem Pendukung Keputusan (Dss) Penyeleksian Pemilihan Penerima Beasiswa Sma N 1 Ulubelu Tanggamus Mengunakan Data Mining" dan masih banyak lagi, dengan hal ini menunjukan penggunaan metode dan algoritma ini sangat tepat dalam melakukan pengelompokan sebuah data segala jenis data yang berhubungan dengan pengelompokan akan lebih mudah dan tersortir menggunaka algoritma K-mean karena proses K-means memiliki beberapa keunggulan seperti sangat mudah dalam implementasi dan pembelajaran penerapannya[9][10].

\section{METODOLOGI PENELITIAN}

Dalam penelitian ini dilakukan beberapa tahapan yang dilakukan secara sistematis, bertujuan untuk memermudah peneliti dalam merngkat prosedur dan rangkaian dalam sebuah penelitian dan lebih terarah, penelitian ini merupakan penelitian yang menggunkan model penelitian kuantitatif[11]. Model kuantitatif ini membantu dan mengarahkan dalam sebuah penelitian dalam bentuk penyelesaian sebuah masalah dalam bentuk penelitian agar pencapaian tujuan penelitian tersebut lebih terarah dengan baik.[12]. Dalam penelitian ini dilakukan pengambilan data dengan menggunakan beberapa teknik penambilan data sebagai berikut:

1. Wawancara

Wawancara merupakan teknik yang paling sering dilakukan dalam pengambilan data sebuah riset bertujuan agar ebih menggali secara detail apa yang ingin didapatkan dalam proses pengambilan informasi tertentu dengan beberapa orang yang terkait.

2. Dokumentasi

Pada proses dokumentasi teknik ini digunakan untuk mendapatkan informasi sekaligus menyimpan data hasil dari informasi yang didapatkan, dokumentasi bias dilakukan dengan cara merekam, video, data-data yang tertuang dalam sebuah kertas dan lainnya.

3. Studi Pustaka

Studi pustaka dilakukan untuk memberikan pandangan yang pernah dilakukan peneliti lain untuk mendapatkan hasil yang maksimal dan lebih detail sebagai bahan pertimbangan dalam pembuatan penelitian[13].

\subsection{Data Mining}

Data mining merupakan sebuah proses untuk menghasilkan informasi yang didapatkan melalui beberapa tahapan dalam mengenali dan memahami pola sebuah data yang sebelumny atida tersedia didalam sebuah database, data mining dapat memenukan sebuah pola kecenderungn data dalam berpasangan antra atribut satu dengan lainnya, menemukan informasi sebagai data bersifat pembagian dalam sebuah cluster, data mining memilik banyak fungsi tergantung kepada kebutuhan dalam menemukan data yang diperlukan, dalam sebuah data mining dikenal dengan teknik Knowledge Discovery in Database singkatan dari KDD dimana tahapan pada KDD ini yag digunakan daam mengelola sebuah pencarian data di dalam sebuah database.[14][15]

\subsection{Clustering}

clustering yang berarti cluster atau pengelompokan adalah salah satu metode dalam sebuah pengelompokan data mining yang digunakan untuk mengkelompokan sebuah data yang banyak untuk melihat setiap data memiliki kemiripan dari masing-masing nilai yang bersifat homogen dan didapat melalui cara pengmatan terhadap objekobjek, data-data yang ingin diketahui cluster dati tiap data tersebut, dalam proses clustering biasanya sebuah data dibantu menggunakan pendekatan sebuah algoritma bertujuan untuk lebih memperinci dan target dalam pengelempokan data jauh lebih terstruktur dalam sistem matematis[16][17].

\subsection{Algoritma K-Means}

Pengelompokan data mahasiswa dengan menggunakan Algoritma K-means, yaitu terdiri dari indeks prestasi kumulatif (IPK) mahasiswa, pendapatan orang tua, disiplin, dan prestasi non akademik. Untuk penelitian ini menggunakan data bantuan dari mahasiswa. Algoritma K-means merupaka algoritma yang di mana akan mengelompokan data kedalam cluster - cluster sehingga jika ada data yang memiliki karkter yang sama maka akan berada pada cluster yang sama dan data yang memiliki ketidak samaan akan berada di dalam cluster yang lain, cara pengelompokan menggunakan k-means yaitu[18]:

1. Menentukan banyaknya yang akan di bentuk ada 4 cluster $(k=4)$. Untuk penentuan cluster harus lebih kecil dari pada banyak nya data $(\mathrm{k}<\mathrm{n})$.

2. Menetukan nilai secara manual atau random untuk pusat cluster awal sebanyak cluster yang ditentukan. 


\section{JURNAL MEDIA INFORMATIKA BUDIDARMA}

Volume 5, Nomor 1, Januari 2021, Page 258-263

ISSN 2614-5278 (media cetak), ISSN 2548-8368 (media online)

Available Online at https://ejurnal.stmik-budidarma.ac.id/index.php/mib

DOI 10.30865/mib.v5i1.2670

3. Untuk menghitung jarak data dengan centroid menggunakan rumus Euclidiean Distance. Persamaan 1 Euclidian Distance

$$
\left.d(x, y)=\sqrt{\sum_{i=1}^{n}\left(x_{i}\right.}-y_{i}\right) 2
$$

4. Mengecek setiap kedekatan data dengan jarak terkecil.

5. Centroid baru akan dihitung dengan melakukan perhitungan nilai rata-rata data pada setiap cluster.

6. Melakuakn perulangan jika perhitungan iterasi yang baru berbeda dengan iterasi sebelumnya, makan peroses akan di lanjutkan ke langkah perulangan selanjutnya. Namun jika iterasi yang baru di hitung memiliki hasil yang sama dengan iterasi belumnya, maka proses clustering selesai. Maka nilai pusat cluster $(\mu j)$ pada iterasi terakhir akan di gunakan sebagai parameter yang dimana untuk menentukan kasifikasi data[19].

\section{HASIL DAN PEMBAHASAN}

Penelitian ini melakukan jarak terpendek antara setiap kriteria dan kondisi yang memiliki jenis dan karakteristik yang hampir sama dengan alternatif lain, dilakukan dua kali iterasi, pada nilai pernyataa untuk prestasi non akademik dan disiplin menggunakan pernyataan sangat baik yang bernilai 100, baik bernila 80, cukup bernilai 60 , buruk bernilai 40 dan sangat buruk bernilai 20, berikut kandidat calon peserta penerima beasiswa Yayasan. Penyelesaian menggunakan algoritma K-means[20].

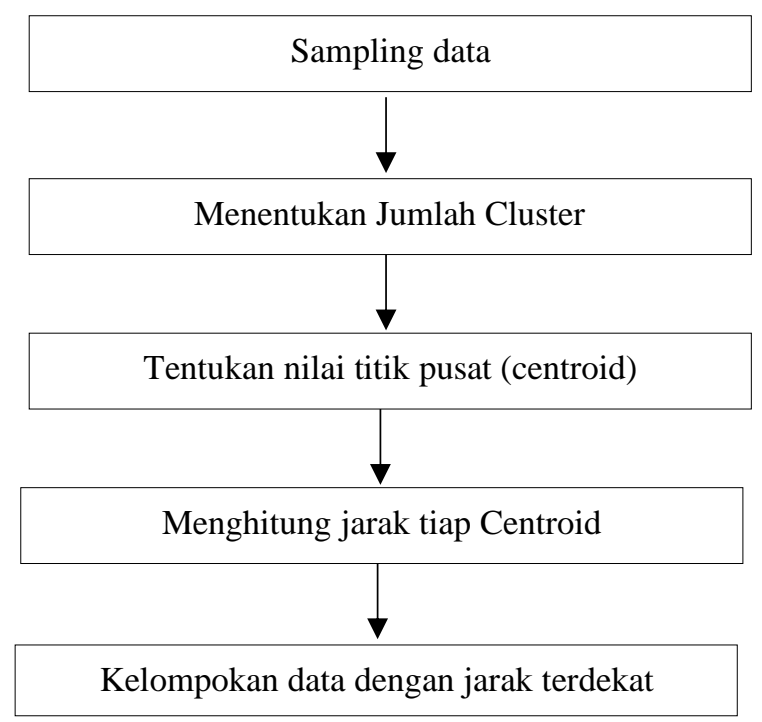

Gambar 1. Kerja Algortima K-Means

Sampling data mahasiswa yang akan dilakukan clustering

Tabel 1. Data Mahasiswa.

\begin{tabular}{cccccc}
\hline No & Nama & IPK & Prestasi N.A & Disiplin & $\begin{array}{c}\text { Penghasilan } \\
\text { Orang Tua }\end{array}$ \\
\hline 1 & Ardiansyah Ritongah & 3.4 & Baik & Baik & 2.500 .000 \\
2 & Amelia Zahra & 2.00 & cukup & Sangat Baik & 3.000 .000 \\
3 & Beni Iskandar & 2.7 & Baik & Baik & 1.500 .000 \\
4 & Budi Prasetya & 3.2 & Cukup & Sangat Baik & 3.000 .000 \\
5 & Cela Arnis & 3.8 & Baik & Baik & 3.000 .000 \\
6 & Citra Purnama & 3.1 & Cukup & Baik & 1.500 .000 \\
7 & Lesti Rahma & 2.79 & Cukup & Sangat baik & 2.400 .000 \\
8 & Risky Brama & 2.66 & Baik & Cukup & 2.300 .000 \\
9 & Yeni Lubis & 2.31 & Buruk & Baik & 2.000 .000 \\
10 & Zizi Arhima & 2.10 & Buruk & Sangat Baik & 2.200 .000 \\
\hline
\end{tabular}

Lakukan peruahan nilai pernyataan dengan mengunakan angka untuk dapat melakukan perhitungan menggunakan algoritma K-means.

Tabel 2. Data Nilai Mahasiswa

\begin{tabular}{cccccc}
\hline No & Nama & IPK & Prestasi N.A & Disiplin & $\begin{array}{c}\text { Penghasilan } \\
\text { Orang Tua }\end{array}$ \\
\hline 1 & Ardiansyah & 3.4 & 80 & 80 & 2.5 \\
\hline
\end{tabular}


JURNAL MEDIA INFORMATIKA BUDIDARMA

Volume 5, Nomor 1, Januari 2021, Page 258-263

ISSN 2614-5278 (media cetak), ISSN 2548-8368 (media online)

Available Online at https://ejurnal.stmik-budidarma.ac.id/index.php/mib

DOI 10.30865/mib.v5i1.2670

\begin{tabular}{cccccc}
\hline No & Nama & IPK & Prestasi N.A & Disiplin & $\begin{array}{c}\text { Penghasilan } \\
\text { Orang Tua }\end{array}$ \\
\hline 2 & Amelia Zahra & 2 & 60 & 100 & 3 \\
3 & Beni Iskandar & 2.7 & 80 & 80 & 1.5 \\
4 & Budi Prasetya & 3.2 & 60 & 100 & 3 \\
5 & Cela Arnis & 3.8 & 80 & 80 & 3 \\
6 & Citra Putri & 3.1 & 60 & 80 & 1.5 \\
7 & Lesti Rahma & 2.79 & 60 & 100 & 2.4 \\
8 & Risky Brama & 2.66 & 80 & 60 & 2.3 \\
9 & Yeni Lubis & 2.31 & 40 & 80 & 2 \\
10 & Zizi Arhima & 2.1 & 40 & 100 & 2.2 \\
\hline
\end{tabular}

Jumlah cluster yang digunakan ada 4 (empat) sama dengan jumlah kriteria yang terdapat pada data sampel, kemudian tentukan nilai centroid atau nilai pusat, nilai-nilai yang diambil sebagai nilai centroid dari data secara acak.

Tabel 3. nilai centroid awal/titik pusat

\begin{tabular}{cccccc}
\hline Ardiansyah & C1 & 3.4 & 80 & 80 & 2.5 \\
Budi Prasetya & C2 & 3.2 & 60 & 100 & 3 \\
Lesti Rahma & C3 & 2.79 & 60 & 100 & 2.4 \\
Zizi arhima & C4 & 2.1 & 40 & 100 & 2.2 \\
\hline
\end{tabular}

Lakukan perhitungan jarak sebagai berikut:

Cluster 1

$$
\begin{aligned}
& \sqrt{(3,4-3,4)^{2}+(80-80)^{2}+(80-80)^{2}+(2.5-2.5)^{2}}=0 \\
& \sqrt{(2-3,4)^{2}+(60-80)^{2}+(100-80)^{2}+(3-2.5)^{2}}=28,323312 \\
& \sqrt{(2,7-3,4)^{2}+(80-80)^{2}+(80-80)^{2}+(1.5-2.5)^{2}}=1,22065556 \\
& \sqrt{(3,2-3,4)^{2}+(60-80)^{2}+(100-80)^{2}+(3-2.5)^{2}}=28,2893973
\end{aligned}
$$

Cluster 2

$$
\begin{aligned}
& \sqrt{(3,4-3,2)^{2}+(80-60)^{2}+(80-100)^{2}+(2.5-3)^{2}}=28,289397 \\
& \sqrt{(2-3,2)^{2}+(60-60)^{2}+(100-100)^{2}+(3-3)^{2}}=1,2 \\
& \sqrt{(2,7-3,2)^{2}+(80-60)^{2}+(80-100)^{2}+(1.5-3)^{2}}=28,323312 \\
& \sqrt{(3,2-3,2)^{2}+(60-60)^{2}+(100-100)^{2}+(3-3)^{2}}=0
\end{aligned}
$$

Cluster 3

$$
\begin{aligned}
& \sqrt{(3,4-2,79)^{2}+(80-60)^{2}+(80-100)^{2}+(2.5-2,4)^{2}}=28,291025 \\
& \sqrt{(2-2,79)^{2}+(60-60)^{2}+(100-100)^{2}+(3-2,4)^{2}}=0,9920181 \\
& \sqrt{(2,7-2,79)^{2}+(80-60)^{2}+(80-100)^{2}+(1.5-2,4)^{2}}=28,29873 \\
& \sqrt{(3,2-2,79)^{2}+(60-60)^{2}+(100-100)^{2}+(3-2,4)^{2}}=0,7276049
\end{aligned}
$$

Cluster 4

$$
\begin{aligned}
& \sqrt{(3,4-2,1)^{2}+(80-40)^{2}+(80-100)^{2}+(2.5-2,2)^{2}}=44,7412561 \\
& \sqrt{(2-2,1)^{2}+(60-40)^{2}+(100-100)^{2}+(3-2,2)^{2}}=20,0162434 \\
& \sqrt{(2,7-2,1)^{2}+(80-40)^{2}+(80-100)^{2}+(1.5-2,2)^{2}}=44,7308618 \\
& \sqrt{(3,2-2,1)^{2}+(60-40)^{2}+(100-100)^{2}+(3-2,2)^{2}}=20,0461966
\end{aligned}
$$

Tabel 4. Data Rekapitulasi Nilai Mahasiswa.

\begin{tabular}{ccccccc}
\hline No & Nama & dc1 & dc2 & dc3 & dc4 & cluster \\
\hline 1 & Ardiansyah & 0 & 28,2893973 & 28,2910251 & 44,7412561 & 1 \\
\hline
\end{tabular}


JURNAL MEDIA INFORMATIKA BUDIDARMA

Volume 5, Nomor 1, Januari 2021, Page 258-263

ISSN 2614-5278 (media cetak), ISSN 2548-8368 (media online)

Available Online at https://ejurnal.stmik-budidarma.ac.id/index.php/mib

DOI 10.30865/mib.v5i1.2670

\begin{tabular}{ccccccc}
\hline No & Nama & dc1 & dc2 & dc3 & dc4 & cluster \\
\hline 2 & Amelia Zahra & 28,323312 & 1,2 & 0,99201814 & 20,0162434 & 3 \\
3 & Beni Iskandar & 1,22065556 & 28,3284309 & 28,2987297 & 44,7308618 & 1 \\
4 & Budi Prasetya & 28,2893973 & 0 & 0,72670489 & 20,0461966 & 2 \\
5 & Cela Arnis & 0,64031242 & 28,2906345 & 28,3086577 & 44,7608088 & 1 \\
6 & Citra putri & 20,0272315 & 20,0564204 & 20,0226397 & 28,3105987 & 3 \\
7 & Lesti Rahma & 20,0272315 & 0,72670489 & 0 & 20,0128983 & 2 \\
8 & Risky Brama & 20,0146846 & 44,7300973 & 44,7216603 & 56,5714027 & 1 \\
9 & Yeni Lubis & 40,0179722 & 28,3159337 & 28,2911718 & 20,0021024 & 3 \\
10 & Zizi Arhima & 44,7412561 & 20,0461966 & 20,0128983 & 0 & 4 \\
\hline
\end{tabular}

Aturan menggunakan cluster berikut ini:

Jika dc1 $<\mathrm{dc} 2$, dc $1<\mathrm{dc} 3$ dan dc $1<\mathrm{dc} 4$ maka = cluster 1

Jika dc2 $<\mathrm{dc} 1, \mathrm{dc} 2<\mathrm{dc} 3, \mathrm{dc} 2<\mathrm{dc} 4$ maka $=$ cluster 2

Jika dc $3<\mathrm{dc} 1, \mathrm{dc} 3<\mathrm{dc} 2$ dan dc $3<\mathrm{dc} 4$ maka= cluster 3

Jika dc $4<\mathrm{dc} 1, \mathrm{dc} 4<\mathrm{dc} 2$ dan dc $4<\mathrm{dc} 3$ maka= cluster 4 .

Sehingga data diatas memperlihatkan data menjadi empat clustering seperti yang tertera pada table diatas, selanjutnya untuk mengetahui jarak antara setiap nilai dilakukan perhitungan iterasi ke dua dengan menggunakan metode dan model yang sama yaitu, model Eucliden, sebelumnya pada iterasi kedua ini nilai centroid awal didapat dari penjumlahan masing-masing cluster 1 dengan cluster 1, cluster 2 dengan cluster 2 dan seterusnya setelah dijumlahkan, cluster tersebut dibagi dengan banyak jumlah masing-masing cluster.

Tabel 5. Data Rekapitulasi Nilai Mahasiswa.

\begin{tabular}{ccrcccc}
\hline No & Nama & \multicolumn{1}{c}{ dc1 } & dc2 & dc3 & dc4 & cluster \\
\hline 1 & Ardiansyah & 81,1020524 & 84,7694003 & 100,354873 & 94,383581 & 1 \\
2 & Amelia Zahra & 85,676891 & 89,6201607 & 104,546709 & 99,146648 & 1 \\
3 & Beni Iskandar & 81,6843409 & 85,1214994 & 100,722093 & 94,6711578 & 1 \\
4 & Budi Prasetya & 85,6366993 & 89,3865924 & 104,265128 & 98,6352817 & 1 \\
5 & Cela Arnis & 80,8152009 & 84,5898038 & 100,164694 & 94,2236561 & 1 \\
6 & Citra putri & 71,8794965 & 73,0828909 & 88,4792149 & 83,2526455 & 1 \\
7 & Lesti Rahma & 85,963214 & 89,5807995 & 104,471263 & 98,7922605 & 1 \\
8 & Risky Brama & 71,3825865 & 72,8867811 & 88,3609365 & 83,4838245 & 1 \\
9 & Yeni Lubis & 66,4940863 & 65,2635016 & 79,6854379 & 76,1644151 & 1 \\
10 & Zizi Arhima & 81,9047813 & 83,4577877 & 97,2582746 & 92,8396867 & 1 \\
\hline
\end{tabular}

Kedekatan hasil pada nilai membuat seluruh cluster menjadi satu cluster, sehingga tampak keseluruhan data memiliki kedekatan jarak terhadap satu dengan yang lainnya, sehingga data dan pembagian terhadap beasiswa dapat dilakukan secara merata berdasar nilai dan pengelompokan dari data tersebut.

\section{KESIMPULAN}

Dari proses pengujian terhadap atribut data dilakukan dalam menentukan kelompok dari masing-masing data yang sudah memiliki nilai tersendiri, penggunaan metode clustering dengan bantuan algoritma K-means merupakan penerapan salah satu metode KDD dalam data mining, pada tahapan cluster yaitu iterasi pertama, terbentuk empat clustering, berdasarkan pembobotan data masing-masing data yang sudah diakumulasikan menggunakan model Eucliden didapatkan empat pengkelompokan dari keseluruhan data, pada iterasi kedua data kembali dihitung menggunakan model Eucliden untuk melihat jarak kedekatan antara satu data dengan data yang lainya, pada hasil akhir terlihat jelas semua data meliliki kedekatan yang sama antara satu dengan lainnya sehingga terbentuk satu pegelomokan berdasarkan jarak kedekatan dengan nilai data.

\section{REFERENCES}

[1] H. S. Tambunan, I. Gunawan, and S. Sumarno, "Prediksi Jumlah Pendapatan Beasiswa PPA dan BBP Menggunakan Jaringan Syaraf Tiruan Backpropagation," J. Media Inform. Budidarma, vol. 3, no. 4, p. 346, 2019, doi: 10.30865/mib.v3i4.1327.

[2] A. P. Utomo, "Pemodelan Arsitektur Enterprise Sistem Informasi Akademik Pada Perguruan Tinggi Menggunakan Enterprise Architecture Planning," Simetris J. Tek. Mesin, Elektro dan Ilmu Komput., vol. 5, no. 1, p. 33, 2014, doi: 10.24176/simet.v5i1.129.

[3] R. Taufiq and H. P. Sari, "Rancang Bangun Sistem Pendukung Keputusan Penentuan Jenis Beasiswa Menggunakan Knn,” J. Tek. Univ. Muhammadiyah Tangerang, vol. 8, no. 1, pp. 6-10, 2019.

[4] M. Mariko and A. Yaqin, "Sistem Pendukung Keputusan Penentuan Calon Penerima Beasiswa Prestasi di Universitas Amikom Yogyakarta," J. Media Inform. Budidarma, vol. 3, no. 3, p. 172, 2019, doi: 10.30865/mib.v3i3.1180.

[5] Assrani dkk., "Penentuan Penerima Bantuan Siswa Miskin Menerapkan Metode Multi Objective Optimization on The 


\section{JURNAL MEDIA INFORMATIKA BUDIDARMA}

Volume 5, Nomor 1, Januari 2021, Page 258-263

ISSN 2614-5278 (media cetak), ISSN 2548-8368 (media online)

Available Online at https://ejurnal.stmik-budidarma.ac.id/index.php/mib DOI 10.30865/mib.v5i1.2670

Basis of Ratio Analysis (MOORA)," JURIKOM (Jurnal Ris. Komputer), vol. 5, no. 2407-389X (Media Cetak), pp. 15, 2018.

[6] S. A. Rahmah, "Klasterisasi Pola Penjualan Pestisida Menggunakan Metode K-Means Clustering ( Studi Kasus Di Toko Juanda Tani Kecamatan Hutabayu Raja ),” J. Inf. Technol. Res., vol. 1, no. 1, pp. 1-5, 2020.

[7] K. D. Maisari, D. Andreswari, and R. Efendi, "Implementasi Metode TOPSIS dengan Pembobotan Entropy untuk Penentuan Calon Penerima Bantuan Siswa Miskin (BSM) APBD Kota Bengkulu( Studi Kasus: SMAN 8 Kota Bengkulu )," J. Rekursif, vol. 5, no. 2, pp. 179-194, 2017.

[8] A. Aditya, I. Jovian, and B. N. Sari, "Implementasi K-Means Clustering Ujian Nasional Sekolah Menengah Pertama di Indonesia Tahun 2018/2019," J. Media Inform. Budidarma, vol. 4, no. 1, p. 51, 2020, doi: 10.30865/mib.v4i1.1784.

[9] N. Rofiqo, A. P. Windarto, and D. Hartama, "Penerapan Clustering Pada Penduduk Yang Mempunyai Keluhan Kesehatan Dengan Datamining K-Means," KOMIK (Konferensi Nas. Teknol. Inf. dan Komputer), vol. 2, no. 1, pp. 216-223, 2018, doi: 10.30865/komik.v2i1.929.

[10] E. Sugiyarti and A. Maseleno, "Sistem Pendukung Keputusan (Dss) Penyeleksian Pemilihan Penerima Beasiswa Sma N 1 Ulubelu Tanggamus Mengunakan Data Mining," Konf. Mhs. Sist. Inf., vol. 6, no. 1, pp. 62-69, 2018.

[11] D. N. Hidayat, "Dikotomi Kualitatif - Kuantitatif Dan Varian Paradigmatik Dalam Penelitian Kualitatif," Scriptura, vol. 2, no. 2, pp. 81-94, 2009, doi: 10.9744/scriptura.2.2.81-94

[12] R. Rahim, E. Buulolo, and N. Silalahi, “C4.5 Algorithm To Predict The Impact Of The Earthquake,” no. January, pp. 2-8, 2017, doi: 10.31227/osf.io/rbwmg.

[13] D. Evanko, "Optical imaging of the native brain," Nat. Methods, vol. 7, no. 1, p. 34, 2010, doi: 10.1038/nmeth.f.284.

[14] D. P. Utomo, "Analisis Komparasi Metode Klasifikasi Data Mining dan Reduksi Atribut Pada Data Set Penyakit Jantung,” vol. 4, no. April, pp. 437-444, 2020, doi: 10.30865/mib.v4i2.2080.

[15] R. S. Harahap, "Komparasi Algoritma Klasifikasi Decision Tree, Naive Bayes Dan Neural Network Untuk Prediksi Penyakit Ginjal Kronis," Konf. Nas. Ilmu Pengetah. dan Teknol., vol. 2, no. 1, pp. 239-INF.244, 2016, [Online]. Available: http://konferensi.nusamandiri.ac.id/prosiding/index.php/knit/article/view/129.

[16] S. Defiyanti, "Integrasi Metode Clustering dan Klasifikasi untuk Data Numerik," Citee, no. July, pp. 256-261, 2017.

[17] E. Buulolo, Buku Data Mining Untuk Perguruan Tinggi, I. 2020.

[18] F. L. Gaol, T. Matsuo, and S. City, "The Digital Transformation of Enterprise Architecture on Culinary SMEs : A Case Study - Culinary SMEs in DKI Jakarta Province," vol. 14, no. 2, pp. 275-289, 2020.

[19] N. Rofiqo, A. P. Windarto, and D. Hartama, "KOMIK (Konferensi Nasional Teknologi Informasi dan Komputer) PENERAPAN CLUSTERING PADA PENDUDUK YANG MEMPUNYAI KELUHAN KESEHATAN DENGAN DATAMINING K-MEANS," [Online]. Available: http://ejurnal.stmik-budidarma.ac.id/index.php/komik.

[20] J. Han, M. Kamber, and J. Pei, "Data Mining: Concepts and Techniques," Data Min. Concepts Tech., 2012, doi: 10.1016/C2009-0-61819-5. 